\title{
Effect of antibiotic-induced intestinal dysbacteriosis on bronchopulmonary dysplasia and related mechanisms
}

\author{
Xiao Ran ${ }^{1,2,3}$, Yu He $e^{1,2,3}$, Qing $\mathrm{Ai}^{1,2,3}$ and Yuan Shi $i^{1,2,3^{*}}$
}

\begin{abstract}
Background: Modification of the gut microbiota by antibiotics may influence the disease susceptibility and immunological responses. Infants in the neonatal intensive care unit (NICU) subjected to frequent antibiotics and oxygen therapies, which may give rise to local and systemic inflammatory reactions and progression of bronchopulmonary dysplasia (BPD). This study aimed to investigate the role of intestinal dysbacteriosis by antibiotic therapy before hyperoxia exposure in the progression of BPD.

Methods: Mice had been exposed to hyperoxia $\left(85 \% \mathrm{O}_{2}\right)$ since postnatal day 3 until day 16 for the BPD model establishment, treated with antibiotics from postnatal day 2 until day 8 . Treated mice and appropriate controls were harvested on postnatal day 2 or 10 for $16 \mathrm{~S}$ rRNA gene sequencing, or postnatal day 17 for assessment of alveolar morphometry and macrophages differentiation.
\end{abstract}

Results: Antibiotic-induced intestinal dysbacteriosis before hyperoxia exposure gave rise to deterioration of BPD evidenced by reduced survival rates and alveolarization. Moreover, antibiotic-induced intestinal dysbacteriosis resulted in increased M1 macrophage maker (iNOS) and decreased M2 macrophage maker (Arg-1) levels in lung homogenates.

Conclusion: Broad-spectrum antibiotic-induced intestinal dysbacteriosis may participate in BPD pathogenesis via alteration of the macrophage polarization status. Manipulating the gut microbiota may potentially intervene the therapy of BPD.

Keywords: Intestinal dysbacteriosis, Bronchopulmonary dysplasia, Macrophages, Gut microbiota, Antibiotic, Neonate

\section{Introduction}

As a multi-factorial chronic lung disease of preterm infants, Bronchopulmonary dysplasia (BPD) subjected to interrupted lung deterioration [1]. It most commonly contributed to long-term morbidity and mortality in effectively low birth body weight (ELBW) babies [2].

\footnotetext{
*Correspondence: shiyuan@hospital.cqmu.edu.cn

1 Department of Neonatology, Children's Hospital of Chongqing Medical University, National Clinical Research Center for Child Health and Disorders; Ministry of Education Key Laboratory of Child Development and Disorders, No.136 Zhongshan 2nd Road, Yu Zhong District, Chongqing 400014, People's Republic of China

Full list of author information is available at the end of the article
}

Therefore, here comes a necessity for the understanding of the mechanisms leading to BPD. Infants in the neonatal intensive care unit (NICU) frequently receive antibiotic therapy [3]. Exposure to antibiotics was one of the most critical factors altering the gut microbiota of neonates $[4,5]$. Immunological homeostasis rely on the microbiota, the metabolites and components of microbiota influence how the host susceptible to many immunological-mediated diseases and disorders [6]. Intestinal dysbacteriosis may influence the pulmonary immunological response through the intestinal-pulmonary axis $[7,8]$. However, the role of intestinal dysbacteriosis in the BPD development remains unclear. Hence, this study

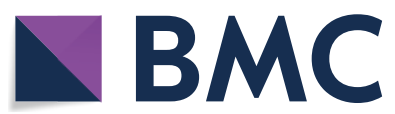

(c) The Author(s) 2021. This article is licensed under a Creative Commons Attribution 4.0 International License, which permits use, sharing, adaptation, distribution and reproduction in any medium or format, as long as you give appropriate credit to the original author(s) and the source, provide a link to the Creative Commons licence, and indicate if changes were made. The images or other third party material in this article are included in the article's Creative Commons licence, unless indicated otherwise in a credit line to the material. If material is not included in the article's Creative Commons licence and your intended use is not permitted by statutory regulation or exceeds the permitted use, you will need to obtain permission directly from the copyright holder. To view a copy of this licence, visit http://creativeco mmons.org/licenses/by/4.0/. The Creative Commons Public Domain Dedication waiver (http://creativecommons.org/publicdomain/ zero/1.0/) applies to the data made available in this article, unless otherwise stated in a credit line to the data. 
aimed to investigate the underlying mechanism and role of intestinal dysbacteriosis in BPD.

\section{Materials and methods Animals}

Pregnant C57BL/6 J mice were bought from the Experimental Animal Center of Chongqing Medical University (Chongqing, China) and were allowed to deliver spontaneously. All animal experiments were carried out pursuant to the protocols approved by the Animal Care and Use Ethics Committee of the Chongqing Medical University (No. 2019389; Chongqing, China). All mice were under the environment where temperature and humidity were controlled (Additional files 1,2).

Antibiotics treatment ( $A B X$ ) and BPD model establishment Neonatal mice were randomly divided into 4 groups: the Saline/Air group; the ABX/Air group; the Saline/ $\mathrm{O}_{2}$ group; and the $\mathrm{ABX} / \mathrm{O}_{2}$ group; $\mathrm{n}=25$ each. We treated the neonatal $\mathrm{C} 57 \mathrm{BL} / 6$ mice with broad-spectrum antibiotics from postnatal day (PN) 2 to PN8. Antibiotics treatment involved oral gavage of ampicillin $(10 \mathrm{mg} / \mathrm{kg}$; Sangon Biotech), vancomycin (5 mg/kg; Sangon Biotech), neomycin sulfate $(10 \mathrm{mg} / \mathrm{kg}$; Sangon Biotech) and metronidazole (10 mg/kg; Sangon Biotech) every 12 h [9-11]. The control mice were perfused with saline every $12 \mathrm{~h}$. Separate therapeutic experiment for mice with antibiotics and with saline was carried out in different cages and the neonatal mice were fed by their mother.

In the case of the BPD model establishment where mice received antibiotics or saline on $\mathrm{PN} 2$, hyperoxia exposure was initiated on PN3. The mouse modeling of BPD was performed pursuant to prior study [12]. Neonatal mice along with their mothers were exposed to hyperoxia $\left(85 \% \mathrm{O}_{2}\right)$ or room air $\left(21 \% \mathrm{O}_{2}\right)$ from PN3 to PN16 for 14 consecutive days (Fig. 1). Dams were rotated between hyperoxia and room air groups every $24 \mathrm{~h}$ to reduce oxygen toxicity and have free access to food and water. Fecal samples were collected at PN2 or PN10, lungs were collected at PN17 (Fig. 1).

\section{Histopathological analysis}

The left lung of every mouse subjected to immersion in $4 \%$ paraformaldehyde, fastening in paraffin, and sectioning at $5 \mu \mathrm{m}$. Sections were stainted with hematoxylin and eosin (HE) and evaluated by light microscopy.

\section{Immunofluorescence}

Lung tissue sections were submerged in the xylene and graded alcohols to deparaffinize and rehydrate, santigen retrieval was done using ethylenediaminetetraacetic acid (EDTA, pH 8.0). Sections blocking with blocking solution containing $10 \%$ donkey serum was performed at room temperature for $30 \mathrm{~min}$. Then Sections incubation was performed with mouse anti-CD68 (1:200, Zenbio), rabbit anti-iNOS (1:200, Zenbio), rabbit anti-Arg-1 (1:200, Zenbio) at $4{ }^{\circ} \mathrm{C}$ overnight. The sections washing and incubation were performed with the secondary fluorescein Alexa Fluor 488 (1:400, green, Beyotime) and Cy3 (1:300, red, Beyotime) antibodies at roomtemperature for $50 \mathrm{~min}$. Furthermore, nuclei was stained with $4^{\prime}$, 6-diamidino-2-phenylindole (DAPI, Leagene) at room temperature for $10 \mathrm{~min}$. Finally, the sections washing and incubation were performed with AutoFluo Quencher (Beyotime) for $5 \mathrm{~min}$ and sections were viewed by fluorescent microscopy (Nikon, Japan).

\section{Western blot analysis.}

Western blotting analysis was made to evaluate the expressions of iNOS and Arg-1 in the lung tissues. Lung tissues lysing in protein lysis buffer and protein concentration were evaluated with the Bradford approach.

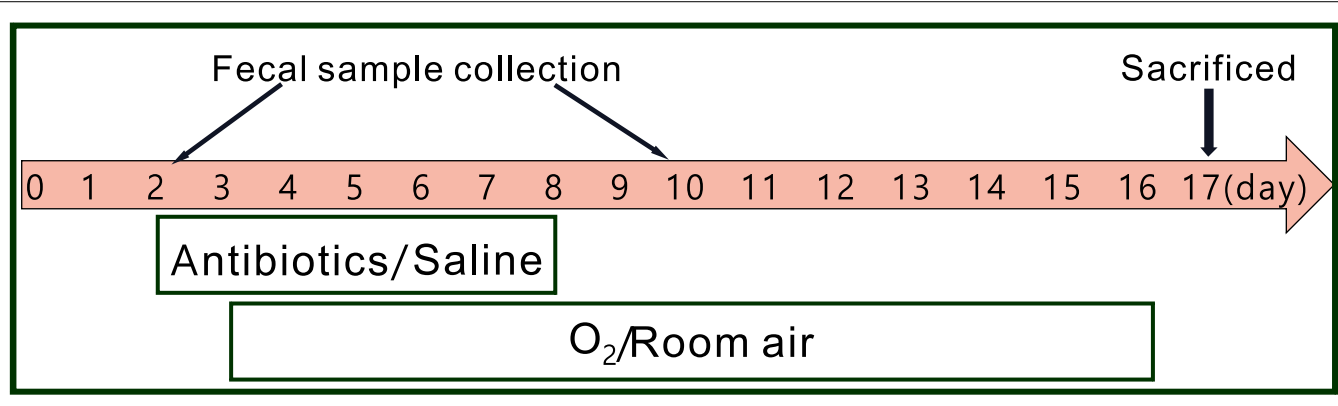

Fig. 1 Treatment regime schematic for the bronchopulmonary dysplasia (BPD) model establishment and administration of antibiotics. The mouse model of BPD was conducted and treated with broad-spectrum antibiotics. The newborn C57BL/6 mice were treated with broad-spectrum antibiotics (ampicillin (10 mg/kg), vancomycin (5 mg/kg), neomycin sulfate $(10 \mathrm{mg} / \mathrm{kg})$ and metronidazole $(10 \mathrm{mg} / \mathrm{kg})$ ) every $12 \mathrm{~h}$ by gavage from postnatal day (PN) 2 to PN8. The control mice were perfused with saline every $12 \mathrm{~h}$ from PN2 to PN8. In the case of the BPD model establishment, the newborn mice were exposed to hyperoxia $\left(85 \% \mathrm{O}_{2}\right)$ from PN3 to PN16. The control mice were exposed to room air $(21 \%$ O 2 ) from PN3 to PN16 
Lysates were separated by sodium dodecyl sulfate polyacrylamide gel electrophoresis (SDS-PAGE) and lysates transfer to polyvinylidene difluoride (PVDF) membranes (Millipore) were made. After $1 \mathrm{~h}$ membranes blocking with TBST buffer containing 5\% non-fat dry for $1 \mathrm{~h}$ at room temperature, membranes incubation was performed with 1:800 anti-iNOS (Zenbio), 1:1000 anti-Arg-1 (Zenbio) and 1:1000 anti- $\beta$-actin (Zenbio) antibody overnight at $4{ }^{\circ} \mathrm{C}$. After membranes washing with TBST (5 min $\times 3$ ), $1 \mathrm{~h}$ membranes incubation was performed at room temperature with a secondary antibody (anti-rabbit IgG, 1:5000; Proteintech) diluted in TBST. Then immunoblots were visualized using ECL kit (Bio-Rad, USA).

\section{Fecal sample collection and assay of commensal bacteria} in the intestine of neonatal mice

Due to the difficulty of gathering sufficient intestinal contents from neonates for $16 \mathrm{~s}$ sequencing, we chose to collect intestinal contents from 6 to 8 neonates per group [13]. We collected the intestinal contents as done previously [4]. QIAamp DNA stool Mini Kit (Qiagen) was applied for the extraction of bacterial DNA from the intestinal contents as instructed by the manufacturer [14]. Illumina MiSeq platform was applied for the sequencing of the 16S rRNA V3-V4 hypervariable region of bacteria according to protocols. The microbial community analysis was conducted as previously reported
[15]. The community structure was analyzed by $\mathrm{R}$ package vegan 2.0 [16].

\section{Statistical analysis}

Statistical analysis was made with SPSS version 22.0. Expression of quantitative data is denoted as mean \pm standard deviation. In addition, unpaired twotailed Student's t-test or ANOVA or Wilcoxon signedrank test was applied for the comparison of differences between groups. $\mathrm{P}<0.05$ was deemed significant in terms of statistics.

\section{Results}

\section{Composition analysis of gut microbiota}

We collected fecal samples before the antibiotics treatment (Day 2), and after seven days of antibiotics therapy (Day 10). Colonization occurs gradually after birth. We found that neonatal mice were mainly colonized with Proteobacteria in the early life (Day 2), and then it was gradually replaced by Firmicutes and Bacteroides (Day 10) (Fig. 2). After seven days of antibiotics therapy, Proteobacteria accounted for a higher proportion at the phylum level, whereas Firmicutes and Bacteroidetes accounted for a reduced proportion in the antibiotics treated mice than that in the saline treated mice (Fig. 2a, b, $\mathrm{P}<0.01)$. At the genus level, the proportion of Citrobacter and unclassified_f_Enterobacteriaceae elevated,

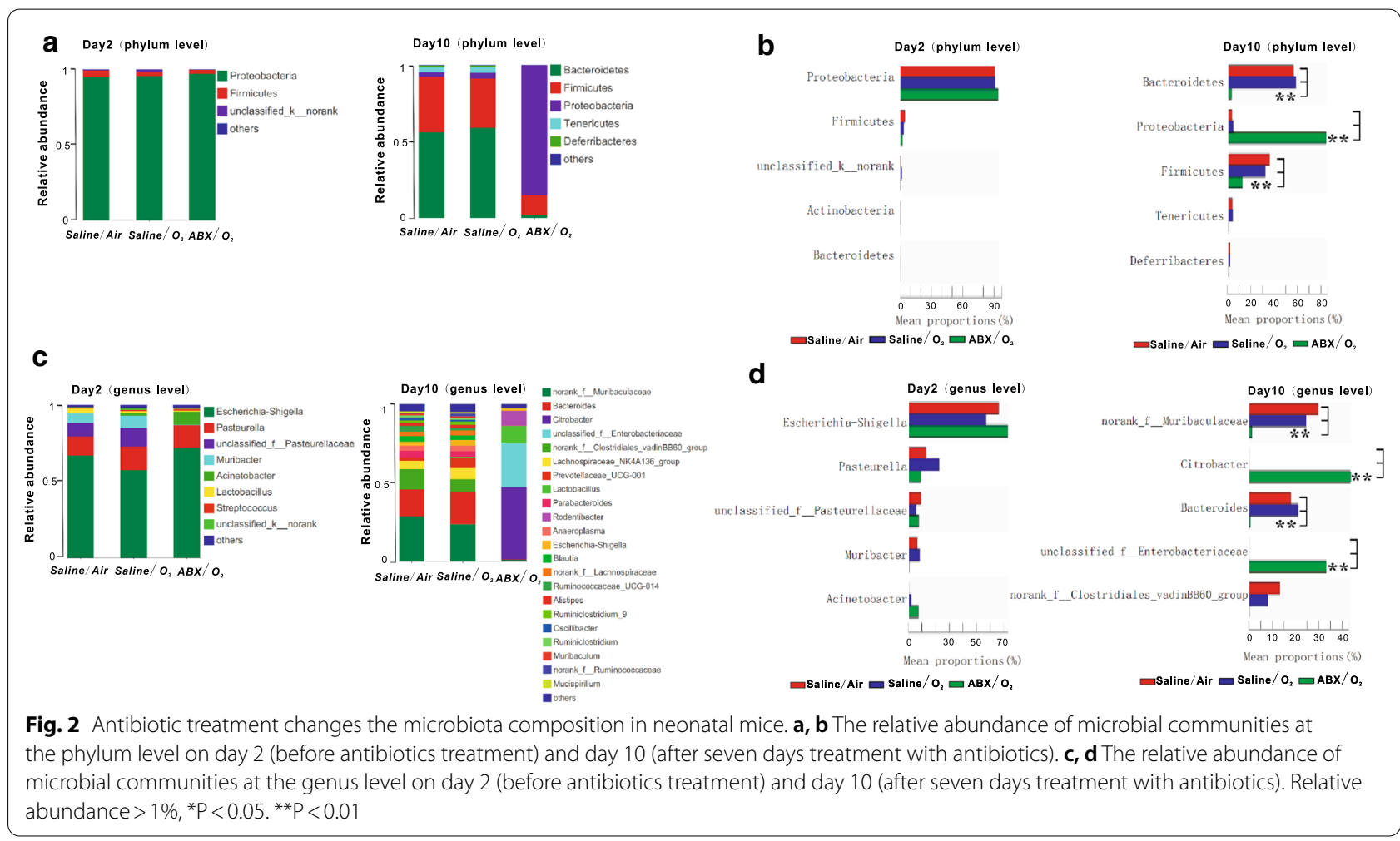


whereas the proportion of Bacteroides and norank $f_{-}$ Muribaculaceae reduced in the antibiotics treated mice than that in the saline treated mice (Fig. 2c, d, P < 0.01).

\section{Effect of antibiotics treatment on survival}

\section{and alveolarization in BPD mice}

The survival rate of BPD mice reduced in the antibiotics treated mice than that in the saline treated mice (Fig. 3a, $\mathrm{P}<0.05$ ). Figure $3 \mathrm{~b}, \mathrm{c}$ showed that, the lungs of $\mathrm{BPD}$ mice had an elevated mean linear intercept (MLI) and decreased radial alveolar count (RAC) after exposed to hyperoxia. Moreover, lungs of mice in the $\mathrm{ABX} / \mathrm{O}_{2}$ group had an elevated MLI and reduced RAC compared to the Saline $/ \mathrm{O}_{2}$ group (Fig. $3 \mathrm{~b}, \mathrm{c}, \mathrm{P}<0.05$ ).

\section{Effects of antibiotics treatment on polarization of macrophages in BPD mice}

As the polarization of macrophages has potential relevance with pathogenesis of BPD [17], we observed whether the antibiotics treatment aggravated BPD via M1/M2 polarization pathways. The polarization of macrophages was identified by double immunofluorescence staining using anti-iNOS (M1) antibodies, anti-Arg-1 (M2) antibodies (Fig. 4b). The iNOS expression increased in BPD mice and then was upregulated when ABX was added (Fig. 4b). The Arg-1 expression decreased in BPD mice and then was inhibited when $\mathrm{ABX}$ was added (Fig. 4b). Then, the protein levels of iNOS and Arg-1 were detected by western blot. Consistent with the above results, iNOS increased in BPD mice and antibiotics treatment upregulated the expression of iNOS
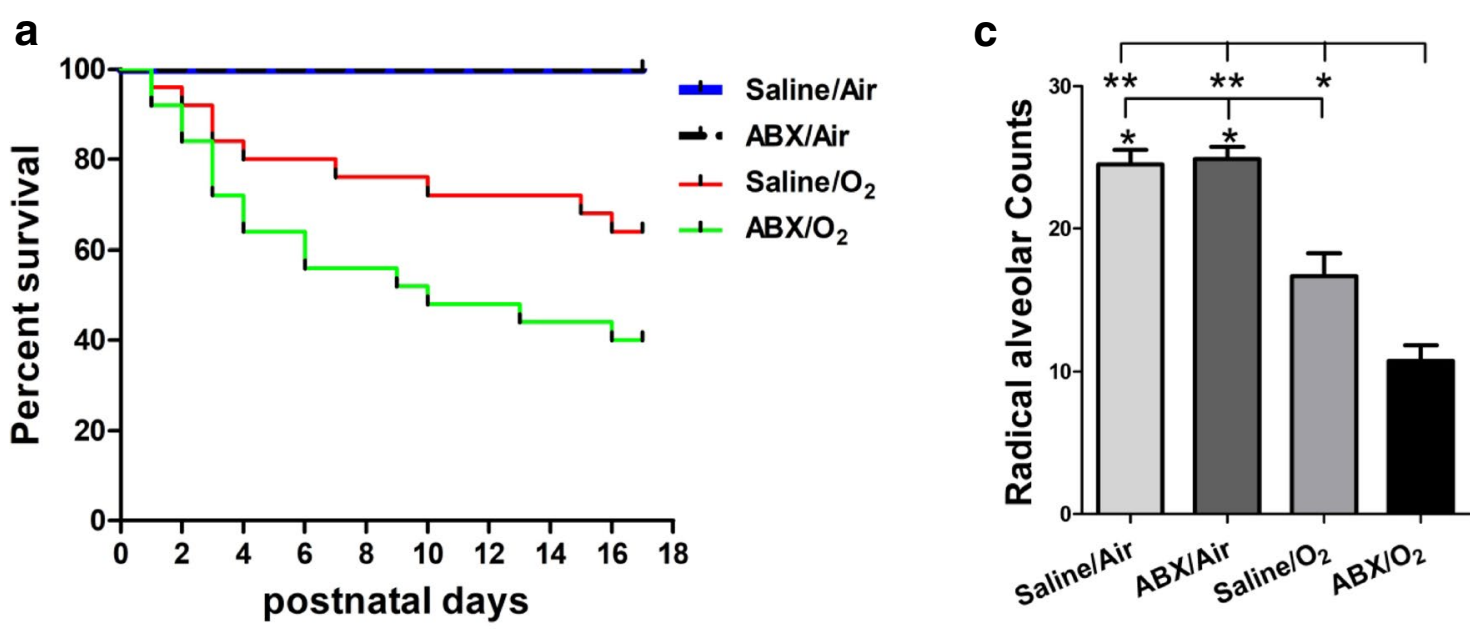
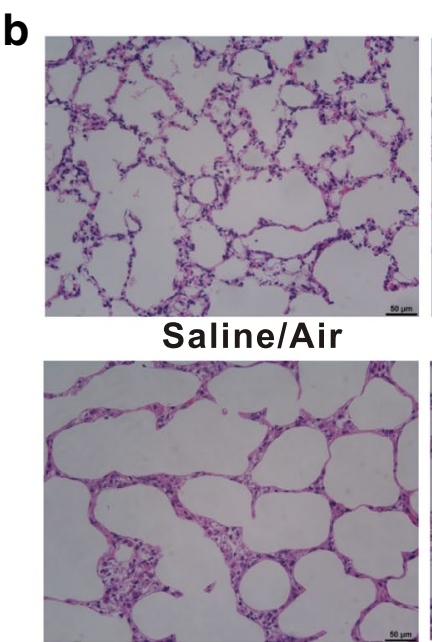

Saline $/ \mathrm{O}_{2}$

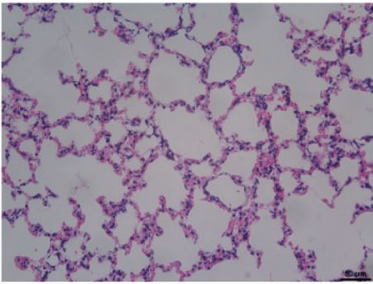

ABX/Air

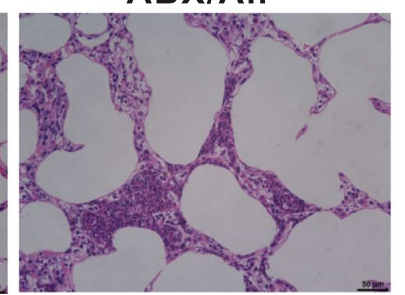

$\mathrm{ABX} / \mathrm{O}_{2}$

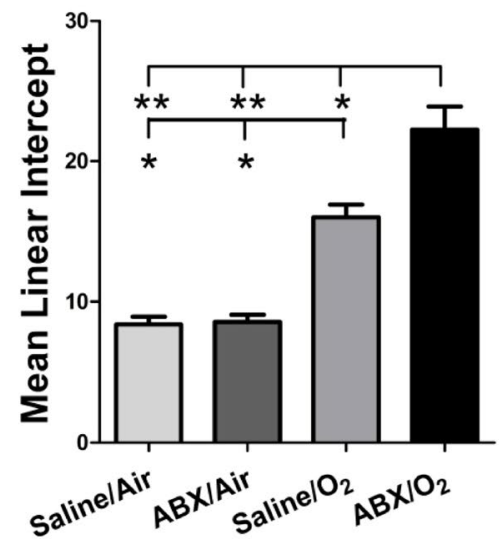

Fig. 3 Effect of antibiotics treatment (ABX) on survival and alveolarization in BPD mice. a Survival of mice in the Saline/Air, $A B X / A i r$, Saline/ ${ }_{2}, A B X /$ $\mathrm{O}_{2}$ groups. The data represent 25 mice per group. b Representative H\&E-stained sections of neonatal lungs in different groups. $\mathbf{c}$ Radial alveolar count (RAC) and mean linear intercept (MLI) of mice in different groups. Data were displayed as mean \pm standard deviation. ${ }^{*} P<0.05$, ${ }^{*} P<0.01$. Results were analyzed using ANOVA 


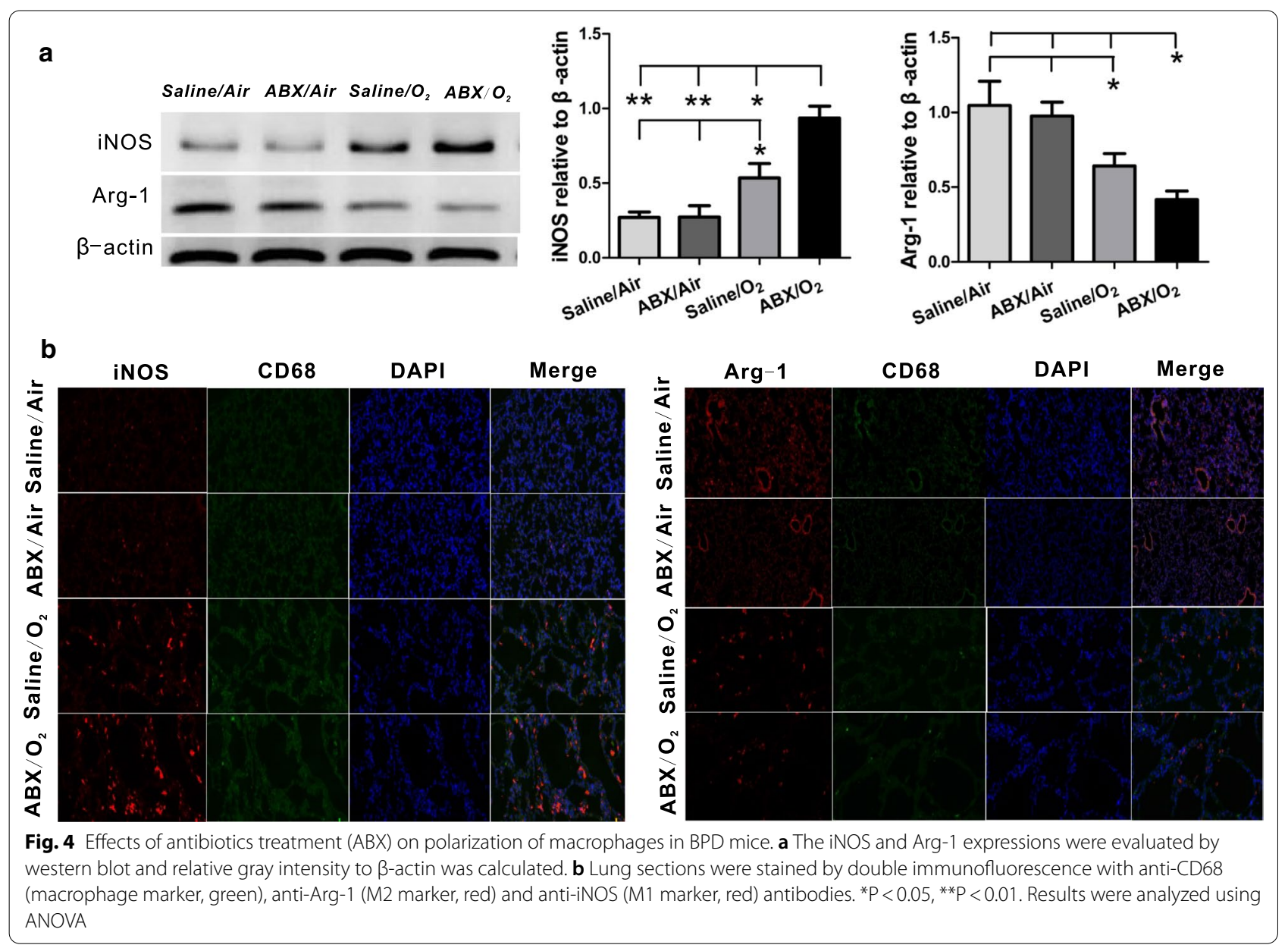

only when mice exposed to hyperoxia (Fig. 4a, P<0.05). Arg-1 decreased in BPD mice and ABX inhibited Arg-1 expression only when mice exposed to hyperoxia (Fig. 4a, $\mathrm{P}<0.05)$. Therefore, with the antibiotics treatment, the ratio of $\mathrm{M} 1$ macrophages increased and the ratio of M2 macrophage decreased in BPD mice, which indicates that ABX upregulated the ratio of M1/M2 macrophages as a pro-inflammatory factor in BPD mice.

\section{Discussion}

In this study we found that antibiotic-induced intestinal dysbacteriosis prior to hyperoxia exposure increased the susceptibility of mouse BPD, evidenced by decreased RAC, increased MLI and increased mortality in the antibiotics treated BPD mice. These findings supported the previous hypothesis that the preterm infants who frequently received antibiotics therapy could develop more severe BPD [18].

$\mathrm{BPD}$ is the most common complicating disease of premature birth. Neonates with BPD usually subjected to respiratory sequelae $[19,20]$. BPD remains a substantial challenge to the neonatologist. Therefore, in this study, we investigated the potential mechanisms of BPD through animal experiments.

Infants in NICU often receive antibiotics treatment. Antibiotics change the composition of gut microbiota. Gut microbiota composition is related to the immunological response. There are increasing evidences that support the concept of cross-talk between the gut microbiota and the lung. For example, Intestinal dysbacteriosis in mice results in abnormal airway allergic responses [21]. Microbiota depletion aggravates ventilator-induced lung injury [22]. These evidences supported that the gut microbiota may affect the lung mucosa by influencing the immunological response. But the participation of antibiotic-induced intestinal dysbacteriosis in the progression of BPD remains unclear. This study researched the effect of intestinal dysbacteriosis on hyperoxia exposure induced the BPD mouse model.

To investigate this interaction, neonates were administrated with a broad-spectrum antibiotic regimen for the induction of intestinal dysbacteriosis. The administration of antibiotics was showed to significantly change the composition of gut microbiota in neonatal mice. We 
found that the relative abundance of the phylum Firmicutes, Bacteroidetes and the genus Bacteroides and norank $f \_$_Muribaculaceae was significantly decreased in the antibiotics treated mice. In contrast, the relative abundance of the phylum Proteobacteria and the genus Citrobacter and unclassified_f_Enterobacteriaceae was significantly increased in the antibiotics treated mice. The findings were consistent with the previous studies, which showed that antibiotics induced intestinal dysbacteriosis could cause decreased relative abundance of phylum Bacteroidetes and Firmicutes and increased relative abundance of Proteobacteria [23, 24].

According to the previous reports, macrophage polarization may play important roles in the development of BPD [25, 26]. When the microenvironment changes, activated macrophages can be M1- or M2-polarized [27]. Modulating the M1/M2 polarization status of macrophages can affect the severity of acute inflammatory conditions of the lung [25]. The M1-polarized macrophage can promote the production of some proinflammatory substances such as iNOS, which participate in inflammation and host defense [28, 29]. The M2-polarized macrophage is involved in tissue repair and tissue remodelling by secreting substances such as Arg-1 [30]. Some research highlighted the importance of Arg-1 in the lung development, as Arg-1 levels in the postnatal lung could be significantly increased during alveolarisation [25]. In this study, we found that antibiotics treatment promoted M1 marker iNOS expression and inhibited M2 marker Arg1 expression in the BPD mice. Hence, antibiotics treatment promoted the macrophages transformation towards pro-inflammatory M1 phenotype and inhibited the macrophages transformation towards anti-inflammatory M2 phenotype. So antibiotics treatment may promote inflammations and inhibit anti-inflammations resulting in the aggravation of BPD. Meanwhile, another study showed that after the composition of gut microbiota were changed and their metabolites were depleted during antibiotic administration, the supplementation of antibiotics with the metabolites could promote the macrophages transformation towards anti-inflammatory M2 phenotype [31]. Based on the above evidences, we suggested that antibiotics treatment may aggravate the mouse BPD via modulating the M1/M2 polarization status of macrophages.

There are limitations need to be considered. Firstly, there was a relatively high mortality in the experimental mice. The reason may be that experiments were conducted in neonatal mice subjected at 2-3 days of life. Secondly, antibiotics administration may affect the results of this study, the administration of antibiotics with fecal microbiota transplants (FMT) may help us to understand the role of microbiota in the development of BPD.

\section{Conclusion}

In summary, our study showed that hyperoxia induced BPD was aggravated by antibiotic-induced intestinal dysbacteriosis in mice, possibly via alteration of the macrophage polarization status. The findings highlight a potentially role of intestinal dysbacteriosis in the BPD pathogenesis. Manipulating the gut microbiota may be a potential therapy of $\mathrm{BPD}$.

\section{Abbreviations}

BPD: Bronchopulmonary dysplasia; ELBW: Extremely low birth weight; PN: Postnatal day; NICU: Neonatal intensive care unit; ABX: Antibiotics treatment; HE: Hematoxylin and eosin; EDTA: Ethylenediaminetetraacetic acid; DAPI: 4', 6-Diamidino-2-phenylindole; SDS-PAGE: Sodium dodecyl sulfate polyacrylamide gel electrophoresis; PVDF: Polyvinylidene difluoride; RAC: Radial alveolar count; MLI: Mean linear intercept; FMT: Fecal microbiota transplants.

\section{Supplementary Information}

The online version contains supplementary material available at https://doi. org/10.1186/s12967-021-02794-6.

Additional file 1: The ethics documents for this study

Additional file 2: Translations of the ethics approvals.

Acknowledgements

We are grateful to all the study participants and their families for their cooperation.

\section{Authors' contributions}

$X R$ and $Y S$ designed the research and drafted the manuscript. YH revised the manuscript. XR and QA made the figures and conducted information collection. All authors read and approved the final manuscript.

\section{Funding}

This work was supported by grants from the National Key R\&D Program of China, the West China Cohort Stuy for Child Health and Development (No. 2019YF(0840703).

\section{Availability of data and materials}

All data generated or analysed during this study are included in this published article.

\section{Declarations}

Ethics approval and consent to participate

The studies were approved by the Animal Care and Use Ethics Committee of the Chongqing Medical University (Chongqing, China).

Consent for publication

Not applicable.

Competing interests

We confirm that none of the authors has any conflict of interest.

Author details

${ }^{1}$ Department of Neonatology, Children's Hospital of Chongqing Medical University, National Clinical Research Center for Child Health and Disorders; Ministry of Education Key Laboratory of Child Development and Disorders, 
No.136 Zhongshan 2nd Road, Yu Zhong District, Chongqing 400014, People's Republic of China. ${ }^{2}$ China International Science and Technology Cooperation Base of Child Development and Critical Disorders, Chongqing, China. ${ }^{3}$ Chongqing Key Laboratory of Pediatrics, Chongqing, China.

Received: 6 January 2021 Accepted: 16 March 2021 Published online: 16 April 2021

\section{References}

1. Jobe AJ. The new BPD: an arrest of lung development. Pediatr Res. 1999:46:641-3.

2. Stoll BJ, Hansen NI, Bell EF, Walsh MC, Carlo WA, Shankaran S, et al. Trends in care practices, morbidity, and mortality of extremely preterm neonates. JAMA. 2015;314:1039-51.

3. Vincent JL, Rello J, Marshall J, Silva E, Anzueto A, Martin CD, et al. International study of the prevalence and outcomes of infection in intensive care units. Jama J Am Med Assoc. 2009;302:2323-9.

4. Deshmukh HS, Liu Y, Menkiti OR, Mei J, Dai N, O'Leary CE, et al. The microbiota regulates neutrophil homeostasis and host resistance to Escherichia coli K1 sepsis in neonatal mice. Idweek Meet Infect Dis Soc Am. 2014;20:524-30.

5. Wang Z, Klipfell E, Bennett BJ, Koeth R, Levison BS, Dugar B, et al. Gut flora metabolism of phosphatidylcholine promotes cardiovascular disease. Nature. 2011:472:57-63.

6. Rooks MG, Garrett WS. Gut microbiota, metabolites and host immunity. Nat Rev Immunol. 2016;16:341.

7. Russell SL, Gold MJ, Willing BP, Thorson L, Mcnagny KM, Finlay BB. Perinatal antibiotic treatment affects murine microbiota, immune responses and allergic asthma. Gut Microbes. 2013;4:158-64.

8. Wang H, Liu JS, Peng SH, Deng XY, Zhu DM, Javidiparsijani S, et al. Gut-lung crosstalk in pulmonary involvement with inflammatory bowel diseases. World J Gastroenterol Wjg. 2013;19:6794-804.

9. Henrik RD, Alexander E, Anders S, Vedrana G, Lars JF, Peter G, et al. Depletion of murine intestinal microbiota: effects on gut mucosa and epithelial gene expression. PLOS ONE. 2011;6:e17996.

10. Schuijt TJ, Lankelma JM, Scicluna BP, Melo FDSE, Wiersinga WJ. The gut microbiota plays a protective role in the host defence against pneumococcal pneumonia. Gut. 2016;65:575-83.

11. Kernbauer E, Ding Y, Cadwell K. An enteric virus can replace the beneficial function of commensal bacteria. Nature. 2014;516:94-8.

12. Nardiello C, Miíková I, Silva DM, Ruiz-Camp J, Mayer K, Vadász I, et al. Standardisation of oxygen exposure in the development of mouse models for bronchopulmonary dysplasia. Dis Model Mech. 2016;10:185-96.

13. Gray J, Oehrle K, Worthen G, Alenghat T, Whitsett J, Deshmukh H. Intestinal commensal bacteria mediate lung mucosal immunity and promote resistance of newborn mice to infection. Sci Translat Med. 2017;9:412.

14. Klingenberg Barfod K, Roggenbuck M, Hestbjerg Hansen L, Schjørring S, Thor Larsen S, Sørensen SJ, et al. The murine lung microbiome in relation to the intestinal and vaginal bacterial communities. BMC Microbiol. 2013;13:1-2.

15. Xiao S, Li Q, Hu K, He Y, Ai Q, Hu L, et al. Vitamin A and retinoic acid exhibit protective effects on necrotizing enterocolitis by regulating intestinal flora and enhancing the intestinal epithelial barrier. Archiv Med Res. 2018:49:1-9.

16. Lozupone C, Lladser ME, Knights D, Stombaugh J, Knight R. UniFrac: an effective distance metric for microbial community comparison. ISME J. 2010;5:169-72.

17. Arora S, Dev K, Agarwal B, Das P, Syed MA. Macrophages: Their role, activation and polarization in pulmonary diseases. Immunobiology. 2017;223:383-96.

18. Wagner BD, Sontag MK, Harris JK, Miller Jl, Mourani PM. Airway microbial community turnover differs by bpd severity in ventilated preterm infants. PLOS ONE. 2017;12:e0170120.

19. Gough A, Spence D, Linden M, Halliday HL, Mcgarvey LPA. General and respiratory health outcomes in adult survivors of bronchopulmonary dysplasia: a systematic review. Chest. 2012;141:1554-67.

20. Bolton CE, Stocks J, Hennessy E, Cockcroft JR, Fawke J, Lum S, et al. The EPICure study: association between hemodynamics and lung function at 11 years after extremely preterm birth. J Pediatr. 2012;161:595.

21. Noverr MC, Noggle RM, Toews GB, Huffnagle GB. Role of antibiotics and fungal microbiota in driving pulmonary allergic responses. Infect Immun. 2004;72:4996-5003.

22. Wienhold SM, Macrì M, Nouailles G, Dietert K, Gurtner C, Gruber AD, et al. Ventilator-induced lung injury is aggravated by antibiotic mediated microbiota depletion in mice. Crit Care. 2018;22:282.

23. Antonopoulos DA, Huse SM, Morrison HG, Schmidt TM, Sogin ML, Young VB. Reproducible community dynamics of the gastrointestinal microbiota following antibiotic perturbation. Infect Immun. 2010;77:2367-75.

24. Uebanso T, Kano S, Yoshimoto A, Naito C, Shimohata T, Mawatari K, et al. Effects of consuming Xylitol on gut microbiota and lipid metabolism in mice. Nutrients. 2017;9:756.

25. Jones CV, Williams TM, Walker KA, Dickinson H, Ricardo SD. M2 macrophage polarisation is associated with alveolar formation during postnatal lung development. Respir Res. 2013;14:41.

26. Syed MA, Bhandari V. Hyperoxia exacerbates postnatal inflammationinduced lung injury in neonatal BRP-39 null mutant mice promoting the M1 macrophage phenotype. Mediat Inflamm. 2013;2013:457189.

27. Gratchev A, Schledzewski K, Guillot P, Goerdt S. Alternatively activated antigen-presenting cells: molecular repertoire, immune regulation, and healing. Skin Pharmacol Appl Skin Physiol. 2001;14:272-9.

28. Sica A, Mantovani A. Macrophage plasticity and polarization: in vivo veritas. J Clin Investigat. 2012;122:787-95.

29. Gordon S, Martinez FO. Alternative activation of macrophages: mechanism and functions. Immunity. 2010;32:593-604.

30. Van Dyken SJ, Locksley RM. Interleukin-4- and interleukin-13-mediated alternatively activated macrophages: roles in homeostasis and disease. Annu Rev Immunol. 2013;31:317-43.

31. Scott NA, Andrusaite A, Andersen P, Lawson M, Alcon-Giner C, Leclaire $C$, et al. Antibiotics induce sustained dysregulation of intestinal T cell immunity by perturbing macrophage homeostasis. Sci Translat Med. 2018;10:eaao4755.

\section{Publisher's Note}

Springer Nature remains neutral with regard to jurisdictional claims in published maps and institutional affiliations.

\footnotetext{
Ready to submit your research? Choose BMC and benefit from:

- fast, convenient online submission

- thorough peer review by experienced researchers in your field

- rapid publication on acceptance

- support for research data, including large and complex data types

- gold Open Access which fosters wider collaboration and increased citations

- maximum visibility for your research: over $100 \mathrm{M}$ website views per year
}

At BMC, research is always in progress.

Learn more biomedcentral.com/submissions 